evidence for the existence of a separate entity of "essential hypernatraemia." 17 In some patients (such as the patient in case 16), however, the condition is masked by dehydration and declares itself only after fluid replacement. The wide variations in fluid requirement and output may be caused by fluctuations in the production of the antidiuretic hormone as a consequence of hypothalamic dysfunction. Because of this we recommend that measurements of plasma and urine osmolality and biochemical indices should be made at least twice daily during the acute phase of the illness. The hypernatraemia that occurred in the two patients in the group with no common factor who had undergone abdominal surgery was probably multifactorial in origin. Dehydration was prominent, but in addition sodium loading with low urinary loss, as occurred in the diabetic patients, played a part. Fluids with high sodium concentrations should, therefore, be used with care when surgery has been carried out for gastrointestinal haemorrhage.

Severe hypernatraemia in adults is uncommon, but patients who are likely to develop it may be identified easily. In established cases frequent measurements of plasma and urine biochemical indices and osmolality are required. Monitoring of central venous pressure is nearly always needed, and patients are best managed in an intensive care unit.

We are grateful to our colleagues who allowed us to study patients under their care and who obtained many additional diagnostic samples; and to the staff of the clinical chemistry laboratory for their help with the analyses and their splendid co-operation. We also pay tribute to the staff of the intensive therapy unit, who contributed in a major way to the successful treatment of many of the patients described in this paper.

\section{References}

1 Swales, J D, Sodium Metabolism in Disease. London, Lloyd-Luke, 1975.

2 Thomas, J H, et al, Lancet, 1978, 1, 621.

${ }^{3}$ Kennedy, P G E, Mitchell, D M, and Hoffbrand, B I, British Medical fournal, 1978, 2, 1251.

${ }^{4}$ Bannister, A, Martin-Siddiqy, S A, and Hatcher, G W, Archives of Disease in Childhood, 1975, 50, 179.

${ }^{5}$ Feig, P U, and McCurdy, M G, New England fournal of Medicine, 1977, 297, 1444.

6 Park, B E, Meacham, W F, and Netsky, M G, fournal of Neurosurgery, 1976, 44, 409.

7 Gammon, H R, Postgraduate Medical fournal, 1975, 51, suppl No 3, p 31.

8 Ware, S, Lancet, 1976, 1, 494.

${ }^{9}$ Boyer, J, Gill, G N, and Epstein, F H, Annals of Internal Medicine, 1967, $67,568$.

${ }^{10}$ Scoggin, C, McClellan, J R, and Cory, J M, Lancet, 1977, 1, 959.

${ }^{11}$ Brenner, W I, et al, Annals of Surgery, 1973, 178, 651.

12 Sament, S, and Schwartz, M B, South African Medical fournal, 1957, 31, 893.

13 Vaisrub, S, fournal of the American Medical Association, 1974, 227, 317.

${ }^{14}$ Jaffe, B, et al, Lancet, 1975, 1, 1069.

15 Blackwell, S W, and Burn-Cox, C J, Postgraduate Medical fournal, 1973, 49, 656.

${ }^{16}$ Clements, R S, Prockop, L D, and Winegrad, A I, Lancet, 1968, 2, 384.

${ }_{17}$ Sridhar, C B, Calvert, G D, and Ibbertson, H K, fournal of Clinical Endocrinology and Metabolism, 1974, 38, 890.

(Accepted 13 March 1979)

\title{
Fibromuscular dysplasia of the renal arteries
}

\author{
MATTIAS AURELL
}

British Medical fournal, 1979, 1, 1180-1181

\section{Summary and conclusions}

Two cases of severe fibromuscular dysplasia of the renal arteries are described in which the diagnosis was made 12 and 11 years after renal angiography had shown the arteries to be normal. The discovery of hypertension preceded the diagnosis by two and 11 years respectively, and in one case hypertension was present at the time of the normal renal angiogram.

The report suggests that fibromuscular dysplasia of the renal arteries is acquired and may not be present from birth. The importance of regular review in cases of severe hypertension is emphasised.

\section{Introduction}

Fibromuscular dysplasia of the renal arteries was first described in the late $1950 \mathrm{~s}^{12}$ Since then several hundred cases have been

\footnotetext{
Department of Medicine, Section of Nephrology, Sahlgrenska Hospital, University of Gothenburg, S-413 45 Gothenburg, Sweden MATTIAS AURELL, MD, associate professor of nephrology
}

reported, mostly from America. ${ }^{3-6}$ The changes in the renal arteries are a common cause of renovascular hypertension, but other vessels, including the splanchnic and the carotid arteries, may also be affected. In a personal, consecutive series of almost 200 cases of renovascular disease $15 \%$ of patients had fibromuscular dysplasia.

The aetiology of the disease is unknown. Women are more often affected than men (female to male ratio 4:1), multiparous women being particularly at risk. Nevertheless, cases have been described in infants and elderly people. Men with the disease often give a history of severe back trauma. No definite conclusions have been drawn about the natural history of the disease, but it has been suggested that it may be present from birth. I therefore report two cases in which renal angiograms were normal 12 and 11 years before severe fibromuscular dysplasia of the renal arteries was diagnosed. So far as I know this is the first such report.

\section{Case 1}

A 38-year-old woman with a family history of hypertension (a brother had died of uraemia due to hypertensive nephropathy) had been investigated at 19 and 23 years of age because of haematuria. No renal abnormality was detected (fig 1), and she was finally diagnosed as having a haemophilic disorder. Over the next 10 years she had four normal pregnancies. The last two deliveries, however, were complicated by placenta praevia and large blood losses, necessitating caesarean section. Raised blood pressure was noted during the fourth pregnancy, and two years later she was reinvestigated. 
Renography suggested a right-sided lesion, and renal angiography (fig 2) showed severe fibromuscular dysplasia of characteristic appearance in both renal arteries. Renin secretion studies showed lateralisation to the right. Reconstructive surgery was considered to be impossible, but the blood pressure was easily controlled with alprenolol $0.2 \mathrm{~g}$ twice daily. Over the next four years (1974-8) her blood pressure remained normal with this treatment, renal function was well maintained, and she remained healthy.

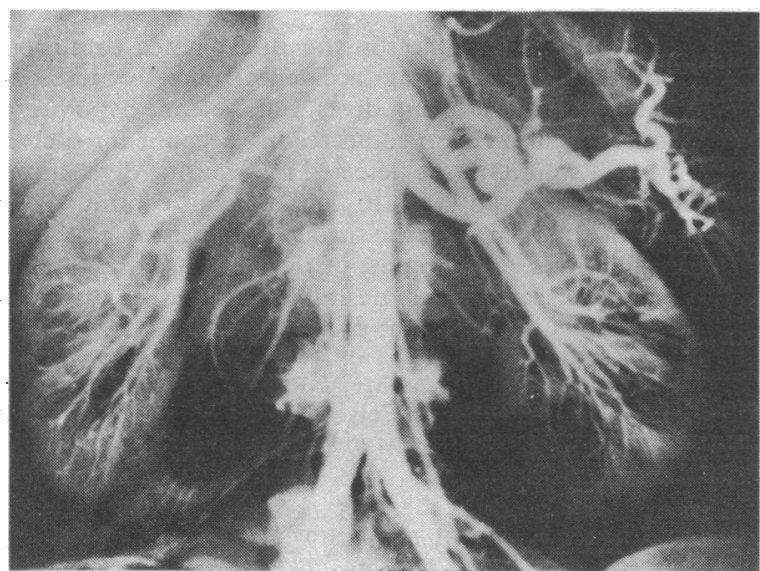

FIG 1-Case 1. Renal angiogram at age 22. Note normal main renal arteries and branches.

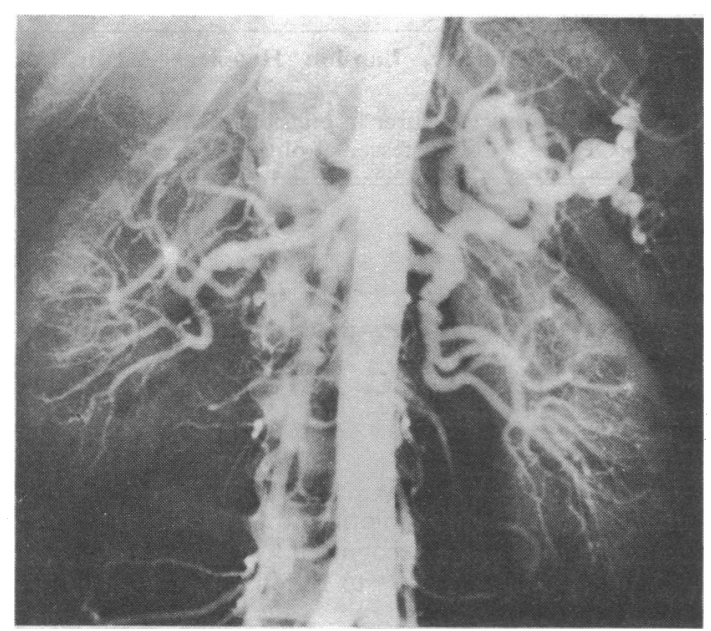

FIG 2-Case 1. Renal angiogram at age 34. Note extensive, characteristic changes in both renal arteries and branches. Changes also evident in splenic artery.

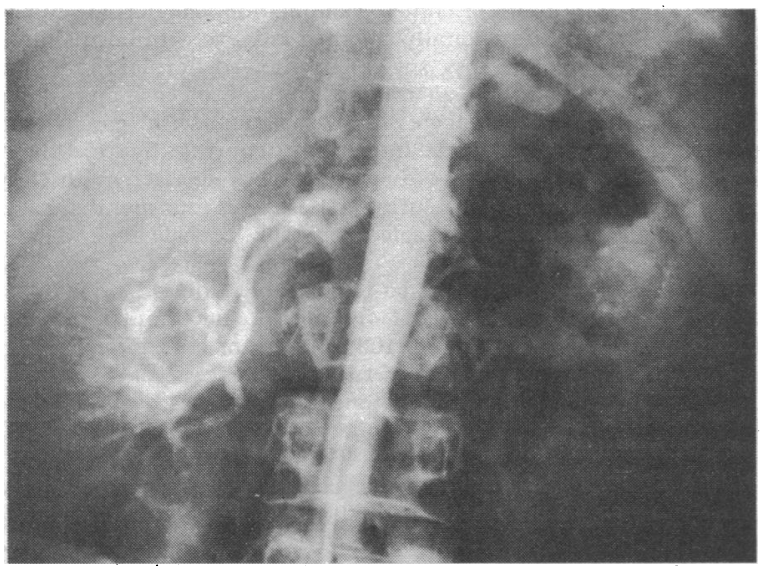

BIG 3-Case 2. Renal angiogram at age 46. Note complete occlusion of left renal artery. Blood supplied to left kidney through collateral vessels. Right renal arteries show severe, characteristic changes. Renal angiogram at age 35 (unfortunately destroyed) was reported to be normal.

\section{Case 2}

This patient, a 46-year-old woman, did not have a family history of hypertension. Hypertension was discovered at age 35 when she was admitted to hospital for depression. Blood pressure had been recorded on several occasions two years before and found to be normal. A spontaneous abortion had occurred seven years earlier and she had subsequently been investigated for sterility. She had also been admitted for investigation of salpingitis, resulting in an operation for obstruction. Extensive clinical work-up included renal function studies and hormonal measurements, and all gave normal results. The renal angiogram was also reported to be normal, but unfortunately the films were destroyed. Over the next few years the hypertension proved difficult to control, but otherwise the patient was in good health. She was reinvestigated at the age of 46 .

Renography showed a left-sided lesion, and the subsequent renal angiogram was grossly abnormal (fig 3 ). There was severe fibromuscular dysplasia of the renal arteries, with total occlusion on the left and severe changes on the right.

\section{Comment}

The disease of the renal arteries in these two patients clearly developed during the 10 years before the diagnosis was made. The diagnosis was based on the "string-of-beads" pattern seen radiologically, which is characteristic of lesions due to medial fibromuscular dysplasia, the most common variant of fibromuscular disease of the renal arteries. ${ }^{7}$ Histological confirmation was not obtained because neither patient underwent operation.

Case 1 was diagnosed only two years after hypertension was discovered, which occurred 10 years after the renal arteries had been seen to be normal. The second patient was diagnosed after more than a decade of treatment for hypertension, and in this patient hypertension was present at the time the first, reportedly normal, renal angiogram was obtained. These films had been destroyed, but it is unlikely that such severe changes would have been overlooked. Nevertheless, minor branch stenoses may have been missed. Functional investigations were not done. The evidence therefore suggests that the vascular disease caused the hypertension. The appearance of hypertension in relation to the renal arterial changes, however, was clearly variable. The course of the disease was also variable. In the first case progression stopped during treatment with alprenolol (1974-8), as judged from the control of hypertension and stable renal function. This suggests that a conservative approach is warranted in patients whose hypertension is easily controlled and renal function uncompromised. The other case progressed until renal function was almost completely lost. Surgical correction at an early stage might have been of value in this patient.

Regular review of patients with severe hypertension is clearly important. We use isotopic renography for this purpose, since a normal renogram is rarely obtained in the presence of renovascular disease. Examination every one to two years should be sufficient and not constitute a hazard to patients.

\section{References}

1 Poutasse, E F, and Dustan, H P, Fournal of the American Medical Association, 1957, 165, 1521 .

${ }^{2}$ DeCamp, P T, and Birckett, R, Surgery, 1958, 43, 134.

3 Hunt, J C, et al, Mayo Clinic Proceedings, 1962, 37, 181.

4 Crocker, D W, Archives of Pathology, 1968, 85, 602.

${ }^{5}$ Foster, J H, et al, Surgery, 1969, 65, 157.

- Stanley, J C, et al, Archives of Surgery, 1975, 110, 561.

7 Youngberg, S P, Sherp, S G, and Strong, C G, Medical Clinics of North America, 1977, 61, 623.

(Accepted 20 March 1979) 